\title{
CLINICAL PROFILE OF MEDIASTINAL MASSES
}

\author{
Gayatri Devi Yellapuㄴ, Usha Rani Numballa², Ramesh Dharavath ${ }^{3}$, Joshua Sarella ${ }^{4}$, Narayana Mood ${ }^{5}$
}

${ }^{1}$ Assistant Professor, Department of Pulmonary Medicine, Andhra Medical College.

${ }^{2}$ Associate Professor, Department of Pulmonary Medicine, Andhra Medical College.

${ }_{3}^{3}$ Senior Resident, Department of Pulmonary Medicine, Andhra Medical College.

4Junior Resident, Department of Pulmonary Medicine, Andhra Medical College.

5Junior Resident, Department of Pulmonary Medicine, Andhra Medical College.

\section{ABSTRACT}

\section{BACKGROUND}

Mediastinal masses are relatively uncommon and continue to be an interesting diagnostic and therapeutic challenge to pulmonologists and thoracic surgeons. Mediastinal tumours represent 3\% of tumours seen within chest. This study is chosen with an aim to assess the clinical profile of mediastinal masses.

\section{AIM}

To study the clinical, radiological, pathological and aetiological profile of mediastinal masses.

\section{MATERIALS AND METHODS}

This was a two-year prospective study conducted at Govt. Chest Hospital, Andhra Medical College, Visakhapatnam, Andhra Pradesh; 30 patients were enrolled into study who fulfilled the inclusion criteria. After detailed history and physical examination, the patients were subjected to various necessary investigations to arrive at aetiological diagnosis. Results were analysed as percentages and compared with other studies.

\section{RESULTS}

The mean age of presentation was 43.6 years with a male-to-female ratio of 3.16:1. Cough, chest pain and breathlessness were most common presenting symptoms. Pallor was the most common presenting sign; $80 \%$ of the cases were anterior mediastinal masses, $13 \%$ posterior and $7 \%$ were middle mediastinal masses; $70 \%$ of the cases were malignant and $30 \%$ of cases were benign. The most common aetiology was lymphoma (30\% of cases) followed by lung cancer and thymoma. Other less common causes were teratoma, bronchogenic cysts, neurofibroma, mediastinal lipomatosis, synovial sarcoma, intrathoracic aneurysm and metastasis. In 2 cases, aetiology was not known.

\section{CONCLUSION}

Mediastinal masses are usually symptomatic at presentation. Malignant lesions were more common and they present with symptoms of mediastinal obstruction. Lymphoma was the most frequent primary mediastinal mass followed by lung cancer and thymoma.

\section{KEYWORDS}

Mediastinal Masses, Lymphoma, Thymoma, Teratoma.

HOW TO CITE THIS ARTICLE: Yellapu GD, Numballa UR, Dharavath R, et al. Clinical profile of mediastinal masses. J. Evolution Med. Dent. Sci. 2016;5(53):3556-3559, DOI: 10.14260/jemds/2016/819

\section{INTRODUCTION \\ Mediastinal masses are relatively uncommon and continue to be an interesting diagnostic and therapeutic challenge to pulmonologists and thoracic surgeons. Although, they tend to be more common in young and middle aged adults, numerous types of mediastinal tumours and cysts affect people of all age groups. ${ }^{1}$ Mediastinal tumours represent $3 \%$ of chest wall tumours. ${ }^{2}$ Mediastinum is defined as the thoracic space that lies between the two pleural cavities. It extends from the thoracic inlet cephalad to the superior surface of the diaphragm caudad.}

Financial or Other, Competing Interest: None.

Submission 10-02-2016, Peer Review 14-06-2016,

Acceptance 20-06-2016, Published 04-07-2016.

Corresponding Author:

Dr. Gayatri Devi Yellapu,

D. No. 55-6-24,

Siva Sankar Nagar, Venkojipalem,

Visakhapatnam-530022.

E-mail: gayatriyellapu@gmail.com

DOI: $10.14260 /$ jemds $/ 2016 / 819$
The paravertebral areas (The costovertebral sulci) situated bilaterally are not truly within the mediastinum, but lesions arising within these regions are classically defined in medical literature as mediastinal in origin. ${ }^{2}$ Since mediastinal space is narrow, any mass is likely to compress the adjacent structures leading to life-threatening emergencies, hence any suspicious mediastinal widening with symptoms of compression should be aggressively investigated.

In infants and children, the primary mediastinal masses in order of decreasing frequency are neurogenic tumours, germ cell tumours, enterogenous (Foregut) cysts, lymphomas, angiomas, lymphangiomas, thymic tumours, stem cell tumours, and pleuropericardial cysts. In adults the masses in decreasing order of frequency are thymomas and thymic cysts, neurogenic tumours, germ cell tumours, lymphomas, enterogenous cysts, pleuropericardial cysts. Recent studies indicate a change in the mix of mediastinal lesions in adults. There is a significant increase in the proportion of Lymphoma, whereas the proportion of other lesions has remained the same. 
In adults $65 \%$ of lesions arise in anterior mediastinum, $10 \%$ in middle mediastinum and $25 \%$ in posterior mediastinum. ${ }^{2}$ This distribution is reversed in children.

Initial step in the evaluation of a mediastinal mass is CT thorax, primarily to localise the mass in one of the compartments and secondly for diagnosis of certain lesions like aortic aneurysm, pericardial fat pad, hiatus hernia where no further investigations are necessary. Other investigations like Fine Needle Aspiration Cytology (FNAC), Core Needle Biopsy (CNB) under image guidance, EBUS TBNA, EUS TBNA, IHC studies and biochemical marker studies have made early and accurate diagnosis a possibility in other conditions. The availability of these investigations made the more invasive procedures like mediastinotomy and mediastinoscopy less necessary.

This study is chosen with an aim to assess the recent trends in the incidence of various types of mediastinal masses, their clinical presentations, radiological characteristics and aetiopathological profile. It is conducted in the Govt. Chest Hospital, Visakhapatnam, Andhra Pradesh.

\section{MATERIALS AND METHODS}

This was a prospective study conducted over a period of two years at Govt. Chest Hospital, Andhra Medical College, Visakhapatnam, Andhra Pradesh; 30 patients were enrolled into the study who were above 12 years of age and who presented with clinical features of mediastinal compression and/or who were found to have mediastinal widening on CXR or mediastinal mass on CT chest imaging. After taking written informed consent, a detailed clinical history and physical examination was done. Routine haematological, biochemical tests, serological tests for HIV/HBS Ag, sputum for AFB staining, CXR P/A and lateral view and contrast enhanced computer tomography of chest were done in all cases. Other investigations like peripheral smear, pleural fluid analysis, cytology, cell block, peripheral lymph node FNAC and excision biopsy and fibre-optic bronchoscopy, FNAC/CNB of masses under ultrasound or CT guidance were done in relevant cases. In some cases Immune Histochemistry (IHC) studies were performed to confirm the diagnosis. Data were analysed as percentages and proportions.

\section{RESULTS}

The mean age of the study group was 43.6 years with range being 17-70 years; $50 \%$ of the mediastinal masses are identified in the third and fourth decade of life; $76.6 \%$ were males and $23.4 \%$ were females with a male-female ratio of 3.16:1. Cough was the most common presenting symptom (93.3\%) followed by chest pain and breathlessness (83.3\%); $13 \%(4 / 30)$ of the patients presented with features of Superior Vena Caval Obstruction (SVCO) and 3.3\% (1/30) presented with bulbar palsy and myasthenic symptoms. Pallor was the most common (80\%) physical finding observed followed by peripheral lymphadenopathy (50\%), clubbing (40\%) and facial swelling (13.3\%). Among 15 patients with peripheral lymphadenopathy 10 had supraclavicular lymphadenopathy and 5 had axillary and inguinal adenopathy.

$80 \%(24 / 30)$ were anterior mediastinal masses, $13 \%$ $(4 / 30)$ were posterior mediastinal masses and $7 \%(2 / 30)$ were middle mediastinal masses (Fig. 1); 36.6\% (11/30) of patients had associated pleural effusions, 20\% (6/30) had associated pericardial effusions and $26.6 \%(8 / 30)$ had associated mediastinal adenopathy. Among the laboratory parameters, anaemia was the most common abnormality found and the mean haemoglobin level was $8.1 \mathrm{gms} \%$ (4-15 gms\%). Lymphocytosis in 4 cases and leukopenia in one case was observed in Non-Hodgkin's Lymphoma (NHL). Peripheral smear was normal in all cases of lymphoma. Among the 11 cases of pleural effusions, one was transudative effusion associated with lymphoma and 10 were exudative effusions. NHL was the most common cause of pleural effusion followed by bronchogenic carcinoma and invasive thymoma.

$70 \%(21 / 30)$ of the cases were malignant and 30\% (9/30) cases were benign lesion (Fig. 2). In most of the cases, diagnosis was confirmed by ultrasound or CT guided FNAC or biopsy/FNAC from supraclavicular lymph node. IHC markers supported the diagnosis in 4 cases of Lymphoma and in 2 cases of Thymoma. Imaging alone was the modality of investigation which confirmed cases like mature teratoma, aneurysm of ascending aorta and mediastinal lipomatosis; 9 of 30 cases were NHL, 8 of them located in anterior mediastinum. An equal incidence of lung cancer and thymoma (4/30-13.3\%) were found, all of which were located in anterior mediastinum. Among four thymoma cases, 3 were malignant and 1 was benign. Out of 4 cases of bronchogenic carcinoma, 3 were small cell variety and one squamous cell variety; 2 cases of neurofibroma and 2 cases of bronchogenic cysts were diagnosed in post-operative specimens by histopathology. One case of metastasis from breast carcinoma and in one case aetiology was not known (Table 1).
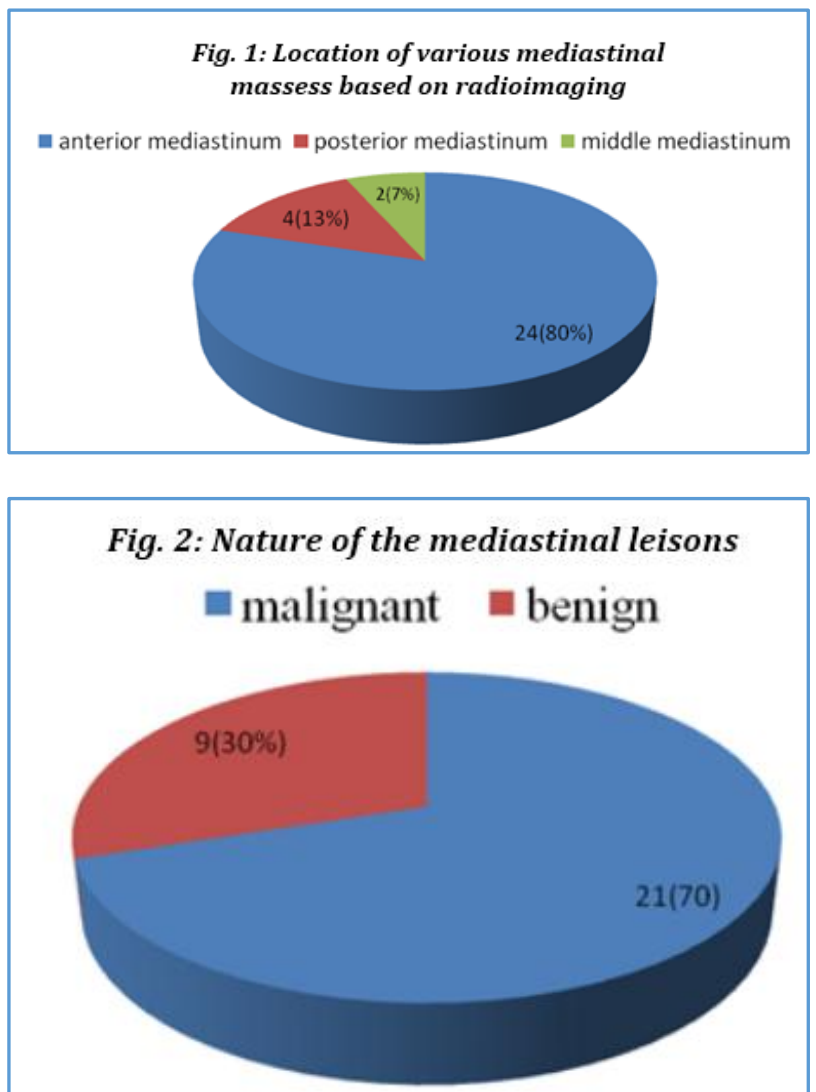

\begin{tabular}{|c|c|c|}
\hline Sl. No. & Case & Number (\%) \\
\hline 1 & Non-Hodgkin's Lymphoma & $9(30 \%)$ \\
\hline 2 & Lung Cancer & $4(13.3 \%)$ \\
\hline 3 & Thymoma & $4(13.3 \%)$ \\
\hline 4 & Teratoma & $3(10 \%)$ \\
\hline
\end{tabular}




\begin{tabular}{|c|c|c|}
\hline 5 & Retrosternal Thyroid Carcinoma & $1(3.3 \%)$ \\
\hline 6 & Mediastinal Lipomatosis & $1(3.3 \%)$ \\
\hline 7 & Synovial Sarcoma & $1(3.3 \%)$ \\
\hline 8 & Intrathoracic Aneurysm & $1(3.3 \%)$ \\
\hline 9 & Metastasis & $1(3.3 \%)$ \\
\hline 10 & Bronchogenic Cyst & $2(6.6 \%)$ \\
\hline 11 & Unknown Aetiology & $1(3.3 \%)$ \\
\hline 12 & Neurofibroma & $2(6.6 \%)$ \\
\hline \multicolumn{2}{|c|}{ Table 1: Aetiology of Various Mediastinal Masses } \\
\hline
\end{tabular}

\section{DISCUSSION}

Mediastinum is the site of variety of lesions, ranging from inflammatory to neoplastic, benign to malignant and primary to metastatic lesions, many of which present as mediastinal masses. The mix of mediastinal lesions has been changing in the past five decades. Proportions of thymoma and lymphoma are on the rise and proportions of other lesions like congenital cysts or germ cell tumours have remained more or less stable. The present study involves 30 cases of mediastinal masses confirmed by radio imaging and their clinical, radiological and aetiological characteristics were analysed.

The mean age of the present study group was $43.66 \pm 7.3$ years with a range of $17-70$ years; $50 \%$ of cases were present in the $3^{\text {rd }}$ and $5^{\text {th }}$ decades of life. In a study by Akshatha Rao Aroor et $\mathrm{al}^{3}$, the mean age of the study group was 45.4 years and most of them were in third and fourth decades, which were similar to our finding. Whereas in other studies by M. Vaziri et $\mathrm{al}^{4}$ and Karkis et $\mathrm{l}^{5}$, the mean age was 34 years with a range of 4 months - 80 years. This was in contrast to our study and this might be because of difference in age group of the study population. In the present study, majority were males who constituted $76.6 \%$ and females were $23.4 \%$ with a male-to-female ratio of 3.26:1. This finding was similar to other studies by Akshatha Rao Aroor et $\mathrm{al}^{3}$ and M. Vaziri et al. ${ }^{4}$

In the present study, all the cases were symptomatic and cough was the commonest symptom (20/30-93.3\%), followed by dyspnoea $(83.3 \%)$ and chest pain $(83.3 \%)$. Symptoms of mediastinal obstruction were present in $66.6 \%$ of patients and dysphagia was commonest (10-33.3\%), followed by hoarseness of voice (20\%) and SVCO (13\%). Myasthenia symptoms were seen in $25 \%$ of thymoma cases. These observations were similar to findings in other studies by Akshatha Rao Aroor et al ${ }^{3}$, Singh et al study. ${ }^{6}$ and Dubashi et $\mathrm{al}^{7}$, except that myasthenic symptoms were seen in $50 \%$ of cases in Akshatha Rao Aroor et $\mathrm{al}^{3}$ study. Whereas in other studies by M. Vaziri et $\mathrm{al}^{4}$, Devis et $\mathrm{al}^{8}$, Cohen AJ et $\mathrm{al}^{9}$ and Adegboye et al $10,12-40 \%$ of the cases were asymptomatic which were identified incidentally on routine chest radiograph and only $60-78 \%$ of cases were symptomatic and their presentation was similar to the present study. This difference in observations could be due to the fact that many of the patients in present study visited the hospital for their symptoms rather than for routine evaluation. As majority of our cases were malignant, it reflects the fact that malignant tumours are more symptomatic than benign tumours.

The most common clinical signs in the present study were pallor (80\%), peripheral lymphadenopathy (50\%), clubbing of fingers and toes (40\%), pedal oedema (33.3\%) and facial swelling (13.3\%), which was similar to other studies. In the present study $80 \%$ of the cases were located in anterior mediastinum, $13 \%$ cases located in posterior mediastinum and $7 \%$ cases located in middle mediastinum which was similar to a study by Vaziri et al. ${ }^{4}$ In studies by Akshatha Rao et $\mathrm{al}^{3}$ and Strollo et $\mathrm{al}^{10}$ anterior mediastinal tumours were more common, but with slight variations in percentages.

Accurate diagnosis is important for the management of mediastinal masses. In the present study, USG/CT guided FNAC as well as CNB of anterior mediastinal masses and FOB with TBNA and IHC markers could diagnose 9 cases of NHL, 4 cases of bronchogenic carcinoma, 4 cases of thymoma, 1 case of retrosternal thyroid, 1 case of synovial sarcoma and metastasis in 1 case. Post-operative tissue biopsy confirmed the diagnosis as neurofibroma and bronchogenic cyst 2 each. No further investigations were done in 5 cases (Mediastinal lipomatosis, intrathoracic aneurysm of aorta and 3 cases of teratoma) since CT alone was sufficient in the diagnosis.

In the present study, $70 \%$ of (21) cases were malignant and $30 \%$ (9) of cases were benign tumours which was similar to other studies by Akshatha Rao et $\mathrm{al}^{3}$ and Vaziri et $\mathrm{al}^{4}$, whereas in other studies by Adegboye et al $^{11}$ and Davis et al ${ }^{8}$ benign lesions were more common which might be because of inclusion of paediatric population in their study groups. Among malignant cases NHL was most common and this was similar to other studies by Akshatha Rao et $\mathrm{al}^{3}$ and Vaziri et $\mathrm{al}^{4}$ and Shrivastav et al. ${ }^{12}$ In other studies like Cohen et al ${ }^{9}$, Davis et $\mathrm{al}^{8}$, Singh et $\mathrm{al}^{6}$ and Dubashi et $\mathrm{al}^{7}$ thymomas were most commonly followed by lymphomas and bronchogenic carcinomas. In Nasit et al ${ }^{13}$ study, the most common tumour was metastatic carcinoma (38\%) followed by NHL.

In the present study, among 9 cases of NHL 4 cases were diffuse large cell B type lymphoma and 2 cases were lymphoblastic lymphoma and 3 cases were other NHL sub types, which was similar to a study by Akshatha Rao et al. ${ }^{3}$ In the present study, among the 4 cases of thymomas 3 cases were malignant and 1 case was benign. This was in contrast to the study by Akshatha Rao et $\mathrm{al}^{3}$, in which among 6 cases of thymoma 5 were benign and 1 case was malignant. In the present study, among 4 cases of bronchogenic carcinoma 3 cases were small cell type and 1 case was squamous cell type. In Akshatha Rao et $\mathrm{al}^{3}$ study, among 7 cases of bronchogenic carcinoma 4 were adenocarcinoma, 2 were squamous cell carcinoma and 1 small cell type.

In the present study, germ cell tumours were seen in 3 cases, of which 2 were benign mature teratoma and 1 was immature teratoma. In Akshatha Rao et al ${ }^{3}$ study, Germ cell tumours were seen in 2 cases and both were in the anterior mediastinum, of which 1 was benign mature teratoma and the other was malignant non-seminomatous tumour. In the present study, 2 cases of bronchogenic cysts were identified. One was located in middle mediastinum and another case in posterior mediastinum. In the present study, 2 cases of neurofibroma (6.6\%) were identified and both were located in posterior mediastinum.

The present study highlights the importance of CT thorax in the initial workup of mediastinal masses, not only for localization but also for characterization of masses. Since most of the mediastinal lesions occur in anterior mediastinum and which can be sampled by FNAC or CNB under USG/CT guidance and so more invasive procedures like mediastinoscopy, mediastinotomy and thoracoscopy can be avoided. This when supported by IHC studies, the differentiation between thymoma and lymphoma becomes easier. Lesions like bronchogenic cyst and neurofibroma were 
suspected by CT imaging, but surgical excision proved to be both diagnostic and therapeutic.

\section{LIMITATIONS}

1. Relatively small sample size was the main limitation.

2. Advanced investigations like EBUS-TBNA/EUS-TBNA could not be done because of lack of facilities.

3. After diagnostic evaluation, clinical course and treatment outcomes were not studied.

\section{CONCLUSION}

Mediastinal masses are usually symptomatic at presentation. Majority of the masses were malignant lesions and the symptoms of mediastinal obstruction were significantly higher in malignant lesions, especially in anterior mediastinal masses. Lymphoma was the most frequent primary mediastinal mass and teratoma constituted the commonest benign anterior mediastinal tumour. Early diagnosis by techniques like CT-guided FNAC/biopsy with IHC studies has greatly enhanced the accuracy of the preoperative diagnosis.

\section{REFERENCES}

1. Thomas SW. Primary mediastinal tumours and cysts. General thoracic surgery. $7^{\text {th }}$ ed. Lippincott Williams \& Wilkins 2009:2195-7.

2. Duwe BV, Sterman DH, Musani AI. Tumours of the mediastinum. Chest 2005;128(4):2893-909.

3. Aroor AR, Prakasha RS, Seshadri S, et al. A study of clinical characteristics of mediastinal mass. Journal of clinical and diagnostic Research 2014;8(2):77-80.

4. Vaziri M, Pazooki A, Zahedi-Shoolami L, et al. Mediastinal masses: review of 105 cases. Acta Medica Iranica 2009;47(4):297-300.
5. Kakri S, Chalise S. Analysis of mediastinal lesions: a study of 27 cases. Journal of pathology of Nepal 2011;1(2):1147.

6. Singh G, Amin Z, Wuryantoro, et al. Profile and factors associated with mortality in mediastinal mass during hospitalization at Cipto Mangunkusumo Hospital, Jakarta. Journal of Internal Medicine 2013;45:3-10.

7. Dubashi B, Cyriac S, Tenali SG. Clinicopathological analysis and outcome of primary mediastinal malignancies- a report of 91 cases from a single institute. Ann Thorac Med 2009;4(3):140- 2.

8. Davis RD, Oldham HN, Sabiston DC. Primary cysts and neoplasms of the mediastinum: recent changes in clinical presentation, methods of diagnosis, management and results. Ann Thorac Surg 1987;44(3):229-37.

9. Cohen AJ, Thompson L, Edwards FH, et al. Primary cysts and tumours of the mediastinum. Ann Thorac Surg 1991;51(3):378-86.

10. Stroll DC, Rosado-de-Christensen ML, Jett JR. Primary mediastinal tumours: part II tumours of the middle and posterior mediastinum. Chest 1997;112(5):1344- 57.

11. Adegboye VO, Ogunseyinde AO, Obajimi MO, et al. Presentation of primary mediastinal masses in Ibadan. East African Medical Journal 2003;80(9):484-7.

12. Shrivastava CP, Devgaha S, Ahlawat V. Mediastinal tumours: a clinicopathological analysis. Asian Cardiovasc Thorac Ann 2006;14:102-4.

13. Nasit JG, Patel M, Parikh B, et al. Antero-mediastinal masses: a study of 50 cases by fine needle aspiration cytology and core needle biopsy as a diagnostic procedure. South Asian J Cancer 2013;2(1):7-13. 